\title{
Preface to the topical collection on the 16th International Conference on Environmental Science and Technology
}

\author{
Dimitra Vagiona ${ }^{1} \cdot$ Georgia Pozoukidou ${ }^{1}$
}

Published online: 25 November 2020

C) Springer Nature Switzerland AG 2020

Cities and regions are highly complex systems in terms of their spatial organization and function, as well as their development, management, governance, and policy. They must cope with major urban and economic developments, the challenges posed by climate change, different types of crises (e.g., health, energy, food, financial, and immigration crises), and increasing environmental vulnerability. Interventions, policies, and management should therefore not only accommodate future urban growth but also guarantee environmental sustainability.

In recent years, ecological resilience as well as environmental issues arising from conflict and exposure have received considerable attention both inside and outside of academia. This special issue aims to increase our understanding of urban and regional environmental pressures, conflicts, and vulnerabilities. It focuses on particular environmental issues encountered at a variety of geographical scales, discussing cases of management and possible policy and planning solutions.

The special issue contains extended versions of scientific papers that were presented at the 16th International Conference on Environmental Science and Technology (CEST2019) in Rhodes, Greece, as well as a few invited papers from thematic fields relating to environmental spatial planning and management. These thematic fields resulted from an attempt to promote a synthetic approach and highlight the complementarity and synergy of natural resource management and planning, natural disaster and environmental threat planning and management, the management and planning of marine environments, green spatial planning strategies, and environmental policy instruments. Therefore, this issue has been organized into three distinct sections:

Georgia Pozoukidou

gpozoukid@plandevel.auth.gr

Dimitra Vagiona

dimvag@plandevel.auth.gr

1 Aristotle University of Thessaloniki, Thessaloniki, Greece marine spatial planning, environmental performance of urban areas, and spatial planning as a physical design and societal process, and contains nine papers in total.

The first three papers focus on a critical issue for the Mediterranean area: the management and planning of marine environments with onshore spatial planning. The paper by M. Papageorgiou, E. Beriatos, O. Christopoulou, M.-N. Duquenne, D. Kallioras, S. Sakellariou, Th. Kostopoulou, A. Sfougaris, E. Mente, I. Karapanagiotidis, S. S. Kyvelou, E. Tzannatos, K. Kanellopoulou, and A. Papachatzi focuses on the issue of effective place-based marine spatial planning. Lessons learnt from the study of a pilot marine area in Greece indicate that there are several aspects that are critical to effective marine spatial planning, such as strengthening cross-border cooperation, engaging the maritime regime and stakeholders in governance schemes, and possessing the tools, data, and methodologies needed to apply place-based approaches. The paper by E. Asprogerakas, M. Lazoglou, and P. Manetos focuses more on the application of an ecosystem-based approach through a quantitative method. The authors argue that the intricacy of the interactions between anthropogenic pressures and the marine ecosystem makes it necessary to quantitatively assess the impact of the land uses proposed by local spatial plans. To this end, they use a special index to assess the pressures of existing land-use regulations on the coastal environment. This index is calculated using an ecosystem-based approach, and the need to integrate both onshore and offshore institutional spatial planning is heavily highlighted. Finally, the paper by F. Tseliou and A. Tselepides focuses on the importance of the ecosystem approach for the preservation and conservation of the marine environment. The paper highlights the relevance of the ecosystem approach as a way to comprehend the complexity of the ecological, economic, societal, and cultural interactions, thus facilitating a green economy and sustainable blue growth. Therefore, the authors use the ecosystem approach to optimize the benefits provided by the oceans 
while simultaneously minimizing the pressures exerted by human activities on marine ecosystems.

The next two papers examine the issue of environmental planning through the perspective of urban environmental performance. The paper by S. Dimos, E. Evangelatou, D. Fotakis, A. Mantis, and A. Mathioudaki provides a methodology to evaluate and estimate the performance of one of the most prominent environmental policies: the European Union Emissions Trading System (ETS). To this end, it investigates the impact of storing allowances ("banking") on the allowance price and the power of the financial sector in the trading network of the ETS. Analysis of EU Transaction Log data along with data on the most important allowance price determinants indicate that banking is a notable-though not the dominant—price determinant. Furthermore, studying the role of financial nodes in the ETS network highlights the significant power of financial entities in this network. The paper by Ch. Achillas, Ch. Vlachokostas, and C. Koroneos demonstrates the value of life-cycle management, with a focus on the life-cycle inventory of aluminum production. Life-cycle inventory is considered to be the key but also the most demanding step in the assessment of the environmental impact of a product or process. The authors describe a quantified life-cycle inventory that should prove useful to environmental managers, product designers, and decisionmakers in industry when they attempt to integrate environmental considerations into their respective activities.

The final four papers focus on how spatial planning, as both a physical design process and a societal process, can help resolve policy conflicts, manage natural disasters, and benefit society as a whole. The paper by Y. Theodora addresses the management of the effects of natural disasters on the natural and manmade environment as well as the everyday lives of local communities. To this end, it recognizes the urgent need to establish disaster prevention and management strategies. Spatial planning is becoming a particularly interesting aspect of disaster prevention and management, especially in a context where nongovernmental stakeholders of various forms are beginning to play a critical role in decision making and are thus establishing a new network of social actors. The activation of civil society structures is an emerging challenge, while volunteer action is acquiring new significance, highlighting how crucial it is to ensure that the population is continuously informed and educated in order to maintain awareness and preparedness. The paper by G. Pozoukidou addresses the issue of green infrastructure as a key concept in spatial planning. This paper focuses on the inherent ability of green infrastructure to provide a variety of ecosystem services and deliver a wide range of policy objectives. It proposes a two-step, spatially centered, methodological approach to GI planning that aims to improve land and resource use efficiency. This methodology was found to facilitate the prioritization of competing planning priorities and to promote certain planning objectives, alleviating environmental pressures in urban areas and enhancing urban resilience. The paper by S. Spyridonidou and Dimitra G. Vagiona deals with the efficient development of offshore wind farms in shallow waters and proposes an integrated spatial energy planning approach. The final outcomes of the proposed methodology are the development of a marine site suitability index and an assessment of the effects of different policy orientations for offshore wind farm siting on that index. Several critical "what if" scenarios are applied to test the robustness of the overall suitability index to the subjectivity of expert judgments regarding potential sites and thus to assess the reliability of the proposed methodology. Finally, the paper by P. Xofis, G. Tsiourlis, and P. Konstantinidis deals with the critical issue of fast fire detection and suppression within the first few minutes after ignition. The methodology used is based on the integration of state-ofthe-art remote-sensing techniques, fire behavior simulation results, and field data to develop a fire danger index that can be used to detect areas that are particularly vulnerable to wildfires. The application of the proposed index to a specific region demonstrated that a large part of the study area, which is a natural reserve, is highly vulnerable to wildfires. The integration of such tools into the automatic fire detection system would be expected to significantly improve its detection accuracy and reduce associated losses of property and human lives.

We hope that this special issue, which combines both theoretical and applied aspects, will substantially and creatively contribute to the development of an international scientific dialog on contemporary issues in environmental spatial planning, especially for the Mediterranean area. Finally, the editors would like to thank all the authors for their contributions, as well as the reviewers and the members of the Conference Scientific Board.

The editors,

Dimitra Vagiona and Georgia Pozoukidou 